\title{
Fatigue mitigation of wind turbine system using multiple point model predictive control
}

\author{
Mutharasan Anburaj, Chandrasekar Perumal \\ Department of Electrical and Electronics Engineering, Vel Tech Rangarajan Dr. Sagunthala R\&D Institute of Science and \\ Technology, Avadi, Chennai-600062, India
}

\section{Article Info \\ Article history: \\ Received Jun 7, 2021 \\ Revised Sep 1, 2021 \\ Accepted Sep 8, 2021}

\section{Keywords:}

Fatigue mitigation

Model predictive control

Multiple point MPC

Wind turbine

Wind energy conversion system

\begin{abstract}
A multi-point model predictive control (MPMPC) is widely used for many applications, including wind energy system (WES), notably enhanced power characteristics and oscillation regulation. In this work, MPMPC is adapted to condense the fatigue load of the WES and improve the lifetime of the turbine assembly. The lifetime examination is carried out by considering the three chief parameters: basic lifetime until failure, short-time damage equivalent loads (DELs), and lifetime DELs. The simulation study is performed for two cases: blade root bending moments and tower top bending. Further, fatigue load examination is demonstrated to analyze the effectiveness of the proposed controller. The observed results show that the lifetime analysis of the wind turbine system displayed more excellent characteristics, i.e., $49.50 \%$ greater than MPC. Also, the fatigue load mitigation showed greater magnitude due to the control action of the proposed controller, about $37.38 \%$ grander than MPC. Therefore, the attained outcomes exhibit outstanding performance compared with conventional controllers.
\end{abstract}

This is an open access article under the CC BY-SA license.

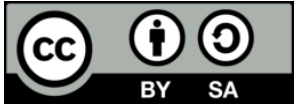

\section{Corresponding Author:}

Mutharasan Anburaj

Department of Electrical and Electronics Engineering

Vel Tech Rangarajan Dr. Sagunthala R\&D Institute of Science and Technology

Avadi, Chennai-600062, India

Email: mutharasanm@gmail.com

\section{INTRODUCTION}

Due to increasing environmental disquiets, attention has shifted to renewable energy sources (RES), namely hydro, wind, and solar [1], [2]. Therefore, a carbon footprint reduces significantly because of fossil fuel usage reduction in the energy sector that enhances the environmentally friendlier RESs [3]-[5]. Notably, world nations and the United Nations environmental monitoring committee have decided to restrain the $\mathrm{CO}_{2}$ emission according to the Paris accord, and the stakeholders of the power industry recently became interested in non-conventional power resources [6], [7]. Notably, wind farms are an attractive means to generate alternative energy, and they experience rapid advances in the last decade [8]. Significantly, wind energy exploitations have gained more popularity among other non-conventional sources. Also, the wind turbine maintenance is substantially less compared to the other Renewable power resources. However, due to wind turbine sizes increasing with bigger rotor diameter, the mechanical fatigue load becomes a significant concern. Therefore, this works aims to reduce the fatigue concentration of wind energy conversion systems (WECS). Based on the needs, a robust literature survey is carried out to examine the existing advancement of the WECS, notably on fatigue concentration of the complete system. The comprehensive method of the literature survey is illustrated in Table 1. 
Table 1. Literature survey on fatigue concentration on WECS

\begin{tabular}{ccl}
\hline Ref. No & Year & \multicolumn{1}{c}{ Methodology } \\
\hline [9] & 2019 & $\begin{array}{l}\text { Three-dimensional pendulum tuned mass } \\
\text { damper (3d-PTMD) }\end{array}$ \\
{$[10]$} & 2018 & $\begin{array}{l}\text { Internal model control (IMC) method with } \\
\text { an adaptive algorithm and individual pitch } \\
\text { control (IPC) }\end{array}$
\end{tabular}

[11] $2017 \quad$ Fore-aft tuned mass damper (TMD)

[12] 2018 Time-domain finite element simulations [13] $2018 \quad \begin{aligned} & \text { Finite element model (FEM) and Brown- } \\ & \text { Miller strain-life method }\end{aligned}$

[14] 2017 Tuned liquid column damper (TLCD)

[15] $2017 \quad$ Sliding mode control theory

2019 T16] Tuned mass damper (TMD) and genetic algorithms

[17] 2018 Finite element model (FEM)

[18] 2018 Wavelet linear quadratic regulator (LQR)

[19] $2017 \quad$ Multiple model predictive control (MPC)

[20] $2017 \quad$ Multiple model predictive control

- Using the Euler-Lagrangian equation, the offshore wind turbine coupled with the 3d-PTMD was established.

- It was noticed that the 3d-PTMD could raise the turbine tower fatigue life about $50 \%$ greater than dual TMDs.

- Simulated results exposed that adapting only IMC or IPC alone had benefits that reduced the fatigue loads on definite components.

- IMC suppressed tower vibrations in both schemes, namely fore-aft, and side-to-side directions, and IPC reduced the fatigue on the shaft, yaw bearings, and blades.

- It established that the high stiffness TMDs unswervingly dissolve the magnitude of tower oscillation that displayed an overall steady enactment.

- TMDs in nacelle/tower could lengthen the lifetime of floating wind turbines.

- Wind turbine action, ecological loads, and adjustable damping heights on the fatigue life were examined scientifically.

- Substantial cost-savings were attained in the wind turbine design using supplemental damping devices.

- Investigations were carried out to evaluate the actual fatigue life, local raceway harm, vibration hastening, and lubrication.

- Three fatigue life computation approaches had distinctive benefits that could mutually be regarded to increase the bearing life calculation accuracy.

- Soil-structure interfaces for a monopile foundation were displayed hypothetically, and a scaled testbed was demonstrated to endorse the outcomes.

- Efficiency of the proposed controller was evaluated for structural vibration reduction.

- The proposed method was adapted to mitigate the torsional vibration of the wind turbine.

- The proposed method enhanced the wind turbine life span.

- The proposed scheme was used to improve the dynamic structural performance of the wind energy system.

- The observed results displayed the improved dynamic responses of the wind turbine adapting a TMD in a floating platform.

- Fatigue damage and torsional vibrations were examined using Palmgren-Miner damage rule, $\mathrm{S}-\mathrm{N}$ curves, and rain flow cycle counting.

- Fatigue predictions using the suggested framework were considerably associated with experimental fatigue outcomes that proved the efficacy and applicability of the proposed framework.

- The proposed scheme was adapted to reduce the blade vibrations.

- Suggested novel wavelet controller attained substantial decline in the out-of-plane response of the blades compared with standard LQR or proportional-integral (PI) controllers.

- The proposed scheme was adapted to control the output power of the NREL 1.5 MW baseline Wind Turbine.

- Simulated results proved that the proposed controller tracked the error effectively and efficiently regulated oscillation in the control signal and mechanical power.

- The entire operating regions of the wind turbine system are divided into several sub-areas based on the wind profile.

- The proposed controller attained better power output characteristics with reduced fluctuation of power generation.

Also, the recently published works demonstrated the application of a vision-based neural network framework for various problems. Notably, Maleewan et al. [21] proposed the evolutionary deep learning model considering the google colab framework to generate and train neural networks. The network was trained using a self-generated dataset of about 12,000 gesture images. In [22] proposed an adaptive networkbased Fuzzy system with a neural network for stereo vision-based image recognition and manipulation. 
Specifically, the vision-based neural network was adapted for agricultural crop defects [23] and end-to-end autonomous driving models [24]. Although these evolutionary models have effective results for various applications, it requires thousands of dataset to execute the network. Due to the insufficient volume of historical failures of wind turbines in a real-time system, vision-based execution may result in imprecise results owing to the limited datasets. MPC shows several advantages for numerous applications such as wind turbines [19], [20], combustion system in power plant [25], attainment of better voltage vector for Induction motor [26], engine torque management [27], speed control of permanent synchronous motor [28] energy management system for PV-battery [29]. It can be easily adapted for diverse applications by considering the operating regions of the model, and that can be sub-divided into several parts for multi-point control. Few works demonstrated the application of multi-point MPC for wind turbines, notably for power output characteristics and oscillation control but not shown for fatigue condensation. Therefore, this work focused on this research gap. The following objectives are derived considering the inferences and limitations from the literature survey:

- To design a novel controller using multi-point MPC.

- To reduce the fatigue magnitude using the proposed controller scheme.

- To increase the lifetime of the WECS.

- To enhance the characteristics of basic short-term and basic lifetime damage equivalent loads (DELs).

- To improve the efficiency of the complete system.

- To reduce the net shear force using a proposed controller.

The rest of the article is structured as shown in: Section 2 presents the modeling of the WECS with required subsystems; Section 3 describes the modeling of the proposed controller; Section 4 demonstrates detailed results and discussions with comparative study; Section 5 concludes the article based on the observed outcome form the proposed scheme.

\section{MODELLING OF WECS}

This section describes a complete model of the WECS that can be arranged as numerous interrelated subsystems, as illustrated in Figure 1. For example, some subsystems are pitch actuator, aerodynamics, generator control, generator model, and drive train.

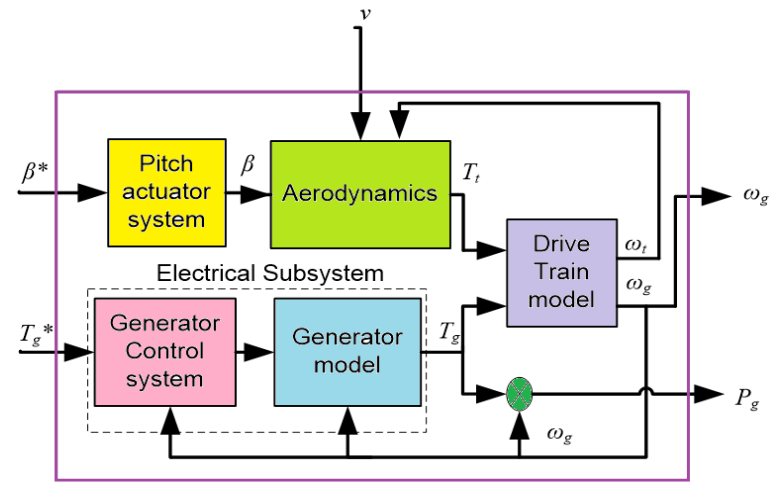

Figure 1. Modeling of WECS

It is a known fact that the overall WECS model considered in this work is nonlinear. Therefore, the linearized turbine torque equations are derived as shown in:

$$
\begin{aligned}
& \xi T_{t}=M_{\omega}\left(\bar{\omega}_{t}, \bar{v}, \bar{\beta}\right) \xi \omega_{t}+M_{v}\left(\bar{\omega}_{t}, \bar{v}, \bar{\beta}\right) \xi v+{ }_{M_{\beta}}\left(\bar{\omega}_{t}, \bar{v}, \bar{\beta}\right) \xi \beta \\
& \left.M_{\omega}\left(\bar{\omega}_{t}, \bar{v}, \bar{\beta}\right)=\left.\frac{\partial T_{t}}{\partial \omega_{t}}\right|_{\left(\bar{\omega}_{t}, \bar{v}, \bar{\beta}\right)}\right) \\
& \left.M_{v}\left(\bar{\omega}_{t}, \bar{v}, \bar{\beta}\right)=\left.\frac{\partial T_{t}}{\partial v}\right|_{\left(\bar{\omega}_{t}, \bar{v}, \bar{\beta}\right)}\right\} \\
& \left.M_{\beta}\left(\bar{\omega}_{t}, \bar{v}, \bar{\beta}\right)=\left.\frac{\partial T_{t}}{\partial \beta}\right|_{\left(\bar{\omega}_{t}, \bar{v}, \bar{\beta}\right)}\right)
\end{aligned}
$$


Where $\xi$ denotes the deviance of the variable from its operational socket. Notably, the operating point of the WECS is entirely demarcated by $\bar{v}$. Then the linearized state-space representation of the WECS is expressed using:

$$
\begin{aligned}
& \dot{a}(t)=\widetilde{\boldsymbol{P}} \boldsymbol{x}(t)+\widetilde{\boldsymbol{Q}}_{\boldsymbol{u}} \boldsymbol{u}(t)+\widetilde{\boldsymbol{Q}}_{\boldsymbol{v}} \xi v(t) \\
& b(t)=\widetilde{\boldsymbol{R}} \boldsymbol{x}(t) \\
& \widetilde{\boldsymbol{P}}=\left[\begin{array}{ccccc}
\frac{L_{\omega}}{J_{t}} & 0 & -\frac{i}{J_{t}} & 0 & \frac{L_{\beta}}{J_{t}} \\
0 & 0 & \frac{1}{J_{g}} & -\frac{1}{J_{g}} & 0 \\
k_{s} i+\frac{i B_{S}}{J_{t}} L_{\omega} & -k_{s} & -\left(\frac{i^{2} B_{S}}{J_{t}}+\frac{B_{S}}{J_{g}}\right) & 0 & \frac{i B_{S}}{J_{t}} L_{\beta} \\
0 & 0 & 0 & -\frac{1}{\tau_{g}} & 0 \\
0 & 0 & 0 & 0 & -\frac{1}{\tau}
\end{array}\right] \\
& \widetilde{\boldsymbol{Q}}_{\boldsymbol{u}}=\left[\begin{array}{cc}
0 & 0 \\
0 & 0 \\
0 & 0 \\
\frac{1}{\tau_{g}} & 0 \\
0 & \frac{1}{\tau}
\end{array}\right] \\
& \widetilde{\boldsymbol{Q}}_{v}=\left[\begin{array}{c}
\frac{L_{v}}{J_{t}} \\
0 \\
\frac{i B_{s}}{J_{t}} L_{v} \\
0 \\
0
\end{array}\right] \\
& \widetilde{\boldsymbol{R}}=\left[\begin{array}{ccccc}
0 & 1 & 0 & 0 & 0 \\
0 & \bar{P}_{g} & 0 & \bar{\omega}_{g} & 0
\end{array}\right]
\end{aligned}
$$

Where

$\boldsymbol{a} \stackrel{\text { def }}{=}\left[\begin{array}{lllll}\xi \omega_{t} & \xi \omega_{g} & \xi T_{t w} & \xi T_{g} \quad \xi \beta\end{array}\right]^{T} \in \mathbb{R}^{5}$ denotes the state vector, $\boldsymbol{u} \stackrel{\text { def }}{=}\left[\begin{array}{ll}\xi T_{g}^{*} & \xi \beta^{*}\end{array}\right]^{T} \in \mathbb{R}^{2}$ represents the control input $\boldsymbol{b} \stackrel{\text { def }}{=}\left[\begin{array}{ll}\xi \omega_{g} & \xi P_{g}\end{array}\right]^{T} \in \mathbb{R}^{2}$ terms the measured output.

\section{PROPOSED METHODOLOGY}

The literature survey perceives that the linear model predictive changes the operating point continuously, leading to degradation notably in the closed-loop performance. Therefore, the researchers carried out a wide-ranging research exertion to encompass the applicability of predictive model control to a nonlinear system. This work attempted to use the MPMPC because the whole operating region is separated into $M$ functioning sub-regions with linearized models that characterize the local scheme dynamics within individual sub-regions. The proposed MPMPC method for the WECS control strategy is illustrated in Figure 2. The proposed scheme comprises three chief components: prediction model bank, optimization problem, and state estimator. The prediction model bank is comprising of $M$ linearized samples that signify the WECS dynamics in the whole working region as described in the figure, and it must be presented (8).

$$
\begin{gathered}
a^{i}(j+1)=A^{i} a^{i}(j)+B_{u}^{i} u(j)+B_{d}^{i} d^{i}(j) \\
b^{i}(j)=C^{i} a^{i}(k)+D_{d}^{i} d^{i}(k)
\end{gathered}, i=1, \ldots M
$$

For the WECS case, control input vector $u(j)$, a state vector $a^{i}(j)$ and controlled output vector $b^{i}(j)$ of scheme $i$ in (1) at the sampling instant $\mathrm{j}$ are as shown in 


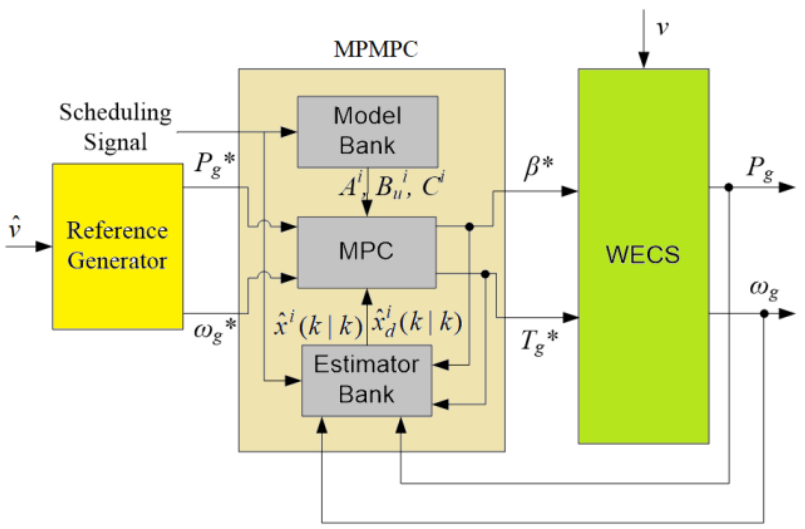

Figure 2. Proposed MPMPC with the control strategy

$$
\begin{aligned}
& a^{i}(j) \stackrel{\text { def }}{=}\left[\begin{array}{lllll}
\delta \omega_{t}^{i}(j) & \delta \omega_{g}^{i}(j) & \delta T_{t w}^{i}(j) & \delta T_{g}^{i}(j) & \delta \beta^{i}(j)
\end{array}\right]^{T} \\
& u(j) \stackrel{\text { def }}{=}\left[\delta T_{g}^{*}(j) \quad \delta \beta^{*}(j)\right]^{T} \\
& b^{i}(j) \stackrel{\text { def }}{=}\left[\delta \omega_{g}^{i}(j) \quad \delta P_{g}^{i}(j)\right]^{T}
\end{aligned}
$$

Further, unmeasured fictitious disturbance $\left(d^{i}(k) \in \mathbb{R}^{n_{d}}\right)$ is adapted to characterize the actual disturbances on the system. Moreover, it is demonstrated as the output of the LTI system as shown in (10).

$$
\begin{gathered}
a_{d}^{i}(j+1)=\bar{A}^{i} a_{d}^{i}(j)+\bar{B}^{i} n_{d}(j) \\
d^{i}(j)=\bar{C}^{i} a_{d}^{i}(j)+\bar{D}^{i} n_{d}(j)
\end{gathered}
$$

It is assumed that $n_{d}(j)$ is random Gaussian noise having zero mean and unit covariance.

Combining the above equations, the amplified prediction model adapted in the MPC construction as shown in (11):

$$
\begin{aligned}
{\left[\begin{array}{c}
a^{i}(j+1) \\
a_{d}^{i}(j+1)
\end{array}\right] } & =\left[\begin{array}{cc}
A^{i} & B_{d}^{i} \bar{C}^{i} \\
0 & \bar{A}^{i}
\end{array}\right]\left[\begin{array}{c}
a^{i}(j) \\
a_{d}^{i}(j)
\end{array}\right]+\left[\begin{array}{c}
B_{u}^{i} \\
0
\end{array}\right] u(j) \\
b^{i}(j) & =\left[\begin{array}{cc}
C^{i}+D_{d}^{i} \bar{C}^{i} & 0
\end{array}\right]\left[\begin{array}{l}
a^{i}(j) \\
a_{d}^{i}(j)
\end{array}\right]
\end{aligned}
$$

Further, quadratic optimization is carried out by assuming information of the plant states estimates $\hat{a}^{i}(j \mid j)$ and disturbance states $\hat{a}_{\boldsymbol{d}}^{i}(j \mid j)$, and applied to time' $j^{\prime}$. The expression for the optimization problem is derived as shown in (12)-(18).

$$
\min _{\forall \Delta T_{g}^{*}(j+k), \Delta \beta^{*}(j+k)}\left\{\begin{array}{c}
\sum_{k=1}^{k=N_{p}} q_{1}^{i}\left(P_{g}^{*}(j+k)-P_{g}^{i}(j+k)\right)^{2}+ \\
\sum_{k=1}^{k=N_{p}} q_{2}^{i}\left(\omega_{g}^{*}(j+k)-\omega_{g}^{i}(j+k)\right)^{2}+ \\
\sum_{k=0}^{k=N_{c}-1} r_{1}^{i} \Delta T_{g}^{* 2}(j+k)+r_{2}^{i} \Delta \beta^{* 2}(j+k) \\
+r_{3}^{i} \beta^{* 2}(j+k)
\end{array}\right\}
$$

Subject to:

$$
\begin{aligned}
& a^{i}(j)=\hat{a}^{i}(j \mid j), a_{d}^{i}(j)=\hat{a}_{d}^{i}(j \mid j) \\
& \Delta \beta_{\text {min }} \leq \Delta \beta^{*}(j+k) \leq \Delta \beta_{\text {max }}, k=1,2, \ldots, N_{c} \\
& \beta_{\text {min }} \leq \beta^{*}(j+k) \leq \beta_{\text {max }}, k=1,2, \ldots, N_{c} \\
& 0 \leq T_{g}^{*} \leq T_{g, \text { max }}, k=1,2, \ldots, N_{c}
\end{aligned}
$$




$$
\begin{aligned}
& \omega_{g}^{i}(j+k) \leq \omega_{g, \text { max }}, k=1,2, \ldots, N_{p} \\
& P_{g}^{i}(j+k) \leq P_{g, \text { max }}, k=1,2, \ldots, N_{p}
\end{aligned}
$$

Where the term 'max and min' is used to signify the maximum and minimum dynamical limit. Also, the terms $T_{g, \max }, \omega_{g, \max }$ and $P_{g, \max }$ are more significant than the rated turbine parameters. Moreover, state observer is used to computing the state estimates comprising of $M$ linear state observers as expressed below. The gain of the scheme $\left(J^{i}\right)$ is calculated using Kalman filtering practices.

$$
\begin{aligned}
& {\left[\begin{array}{l}
\hat{a}^{i}(j \mid j) \\
\hat{a}_{d}^{i}(j \mid j)
\end{array}\right]=\left[\begin{array}{c}
a^{i}(j \mid j-1) \\
a_{d}^{i}(j \mid j-1)
\end{array}\right]+J^{i}\left(b(j)-\left(C^{i}+D_{d}^{i} \bar{C}^{i}\right) \hat{a}^{i}(j \mid j-1)\right)} \\
& {\left[\begin{array}{c}
\hat{a}^{i}(j+1 \mid j) \\
\hat{a}_{d}^{i}(j+1 \mid j)
\end{array}\right]=\left[\begin{array}{cc}
A^{i} & B_{d}^{i} \bar{C}^{i} \\
0 & \bar{A}^{i}
\end{array}\right]\left[\begin{array}{c}
\hat{a}^{i}(j \mid j) \\
\hat{a}_{d}^{i}(j \mid j)
\end{array}\right]+\left[\begin{array}{c}
B_{u}^{i} \\
0
\end{array}\right] u(j)}
\end{aligned}
$$

\section{RESULTS AND DISCUSSIONS}

\subsection{Turbine characteristics}

The proposed scheme is simulated to analyze the turbine characteristics. Initially, the generated wind field is examined on the blade, and the observed feature is shown in Figure 3. It exposes the magnitude of the generated wind with respect to time; maintained between 10 to 22 RPM. Further, pole-zero mapping is examined for two cases i.e., open-loop and closed-loop systems which are illustrated in Figures 4 (a) and 4 (b). It is perceived that the both cases mapped the poles sufficiently. It represents the effectiveness of the proposed approach for the wind energy system.

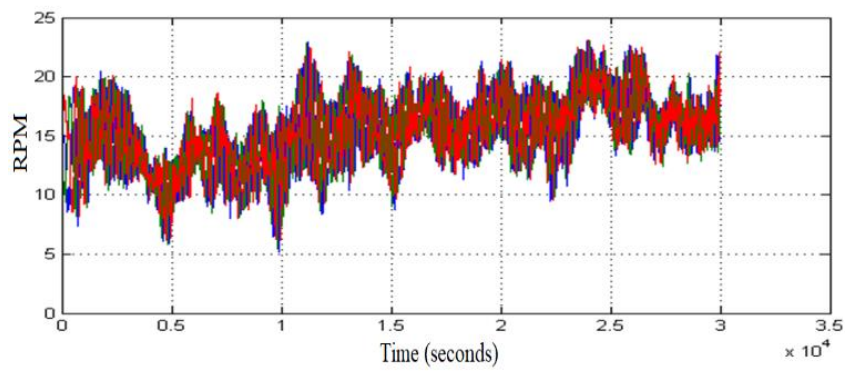

Figure 3. Wind field generated

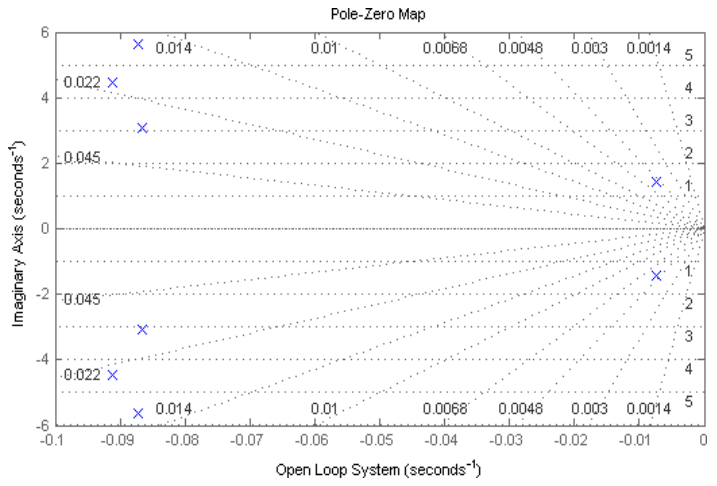

(a)

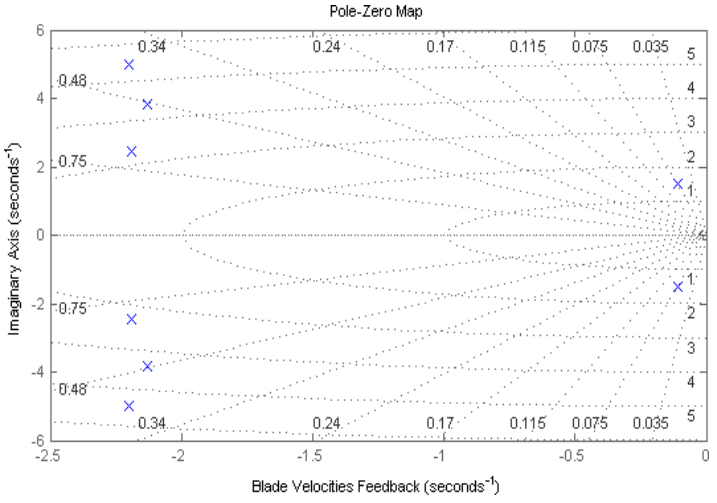

(b)

Figure 4. Pole zero mapping (a) open loop system (b) closed loop system 
Also, the turbine fatigue of the WECS is evaluated for two states, i.e., with MPC and MPMPC. The simulated characteristic and their comparative state of the fatigue is illustrated in Figure 5. It is noticed that the MPMPC performed well with declined fatigue concentration compared with MPC. This is due to the effective control action of multi-point factors applied in the MPMPC approach. The regulation of the proposed system is performed using MPMPC sub-regions; notably, pitch angle for the individual blades, and the experimental plots are given in Figure 6. It is observed that the control action is performed for all three blades uniformly. Therefore, it can enhance the overall performance of the WECS to attain higher efficiency with lower fatigue magnitude.

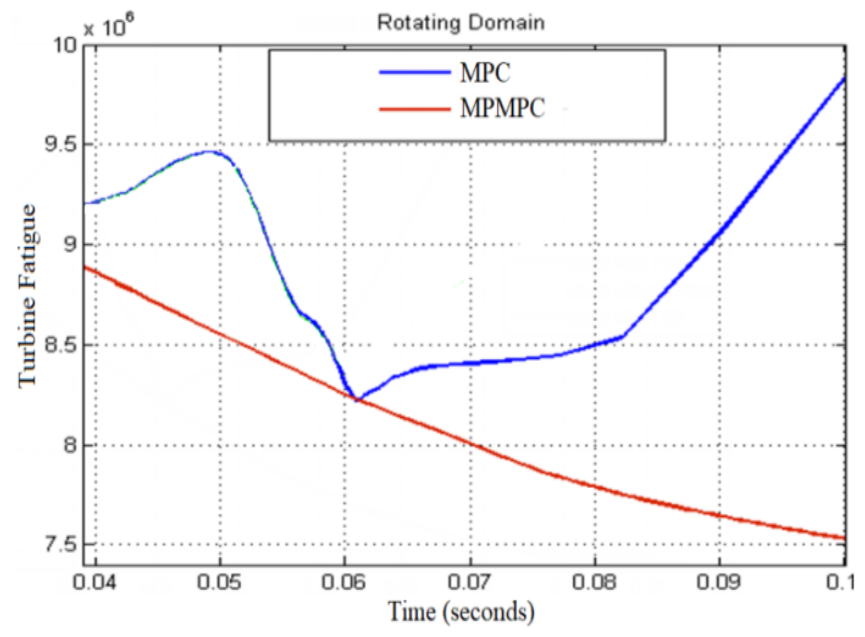

Figure 5. Turbine fatigue characteristics
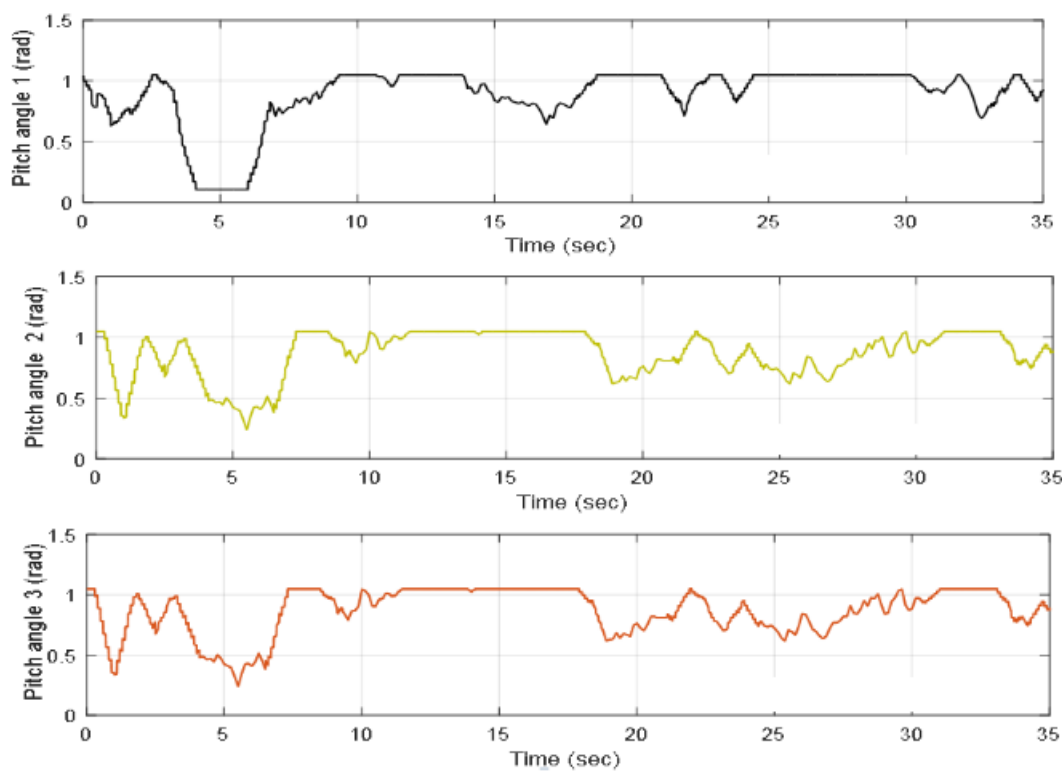

Figure 6. Control action for Individual blades

Further, the edgewise bending moments are scrutinized for the individual blades against time variation, and the observed characteristics are illustrated in Figure 7 for two controllers. The proposed controller shows more excellent performance compared with MPC on all blades. Additionally, the generated power from the turbine and shaft speed are evaluated and illustrated in Figures 8 (a) and 8 (b). The active generated power attained a significant magnitude as represented in the figure, and the shaft speed increased from lower to higher scale linearly. 


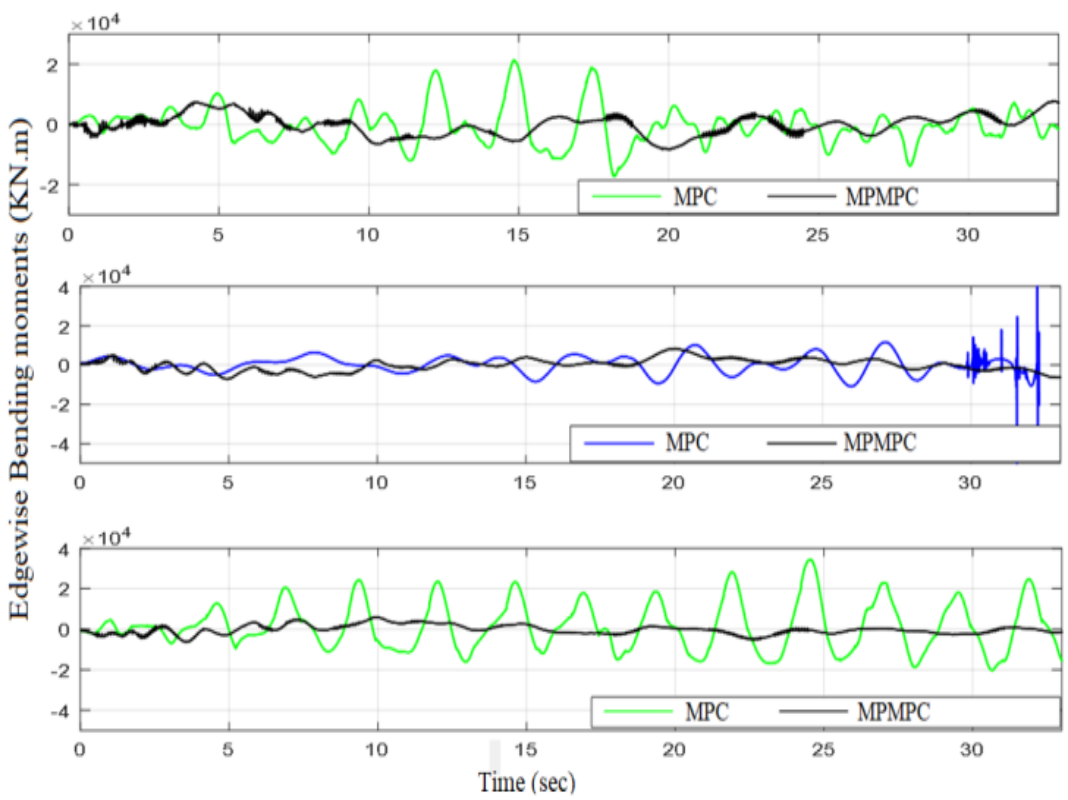

Figure 7. Edgewise bending moment

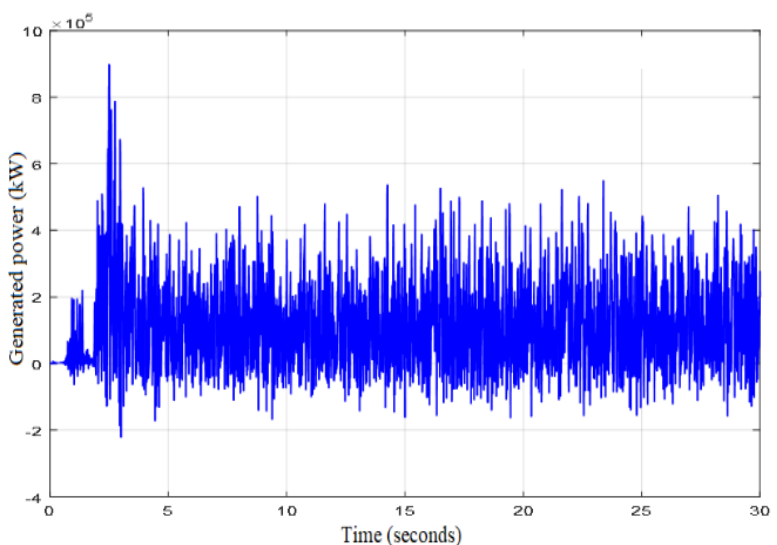

(a)

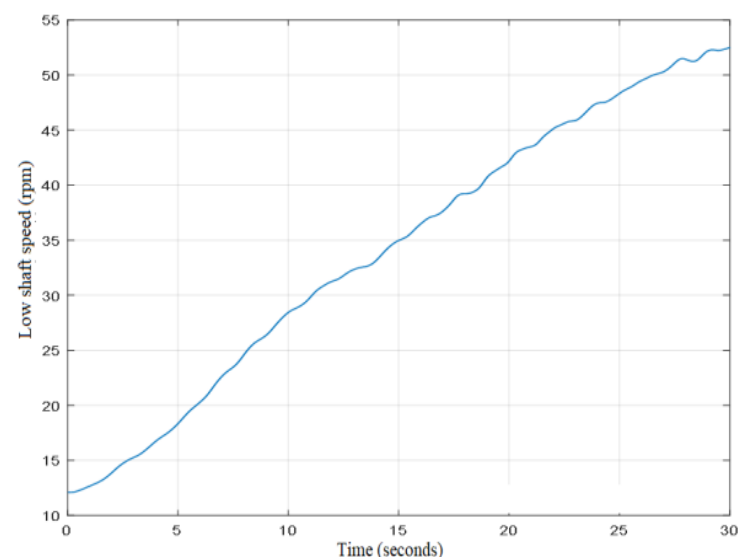

(b)

Figure 8. There figures are (a) power generated (b) shaft speed of wind turbine

\subsection{Lifetime analysis}

To endorse the effectiveness of the suggested control scheme, a statistical examination of the above illustrated simulation outputs is executed considering the below parameters: basic lifetime until failure, DEL (Short term), DEL (Lifetime)

The statistical forecast of the lifespan of the WT mechanisms is hinge on the force and moments detected at diverse elements of the WT. In this work, two factors are adapted for analysis with blade root and tower top; Root flap-wise and edgewise shear force (blade bending moment). Tower top flap-wise and sideside shear force (tower top deflection).

\subsubsection{Blade root bending moment}

The lifespan examination based on the blade root bending moment of the distinct blade is studied, and the perceived results are illustrated in Figures 9 (a)-(d). The basic lifetime (until failure) shows an exceptional performance for MPMPC compared with other controllers, namely MPC, LQBC, and PI. Further, basic short-term and basic lifetime DELs offer improved characteristics for the proposed MPMPC controller. Also, the range of bending moments of the suggested controller is less associated with other conventional controllers that display the efficiency of the suggested control arrangement for WECS. 


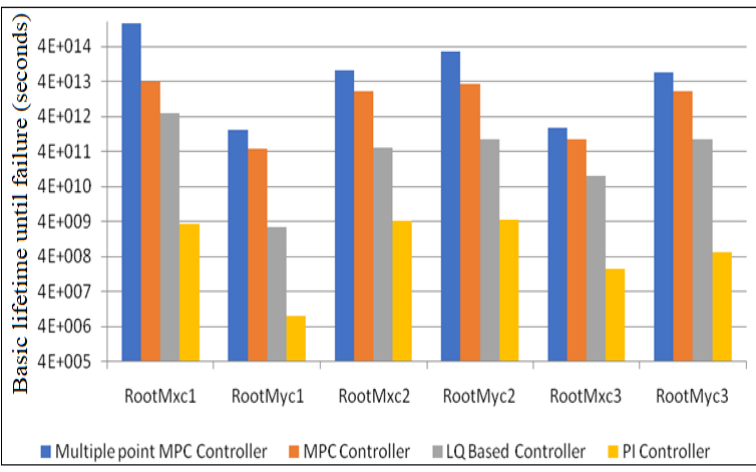

(a)

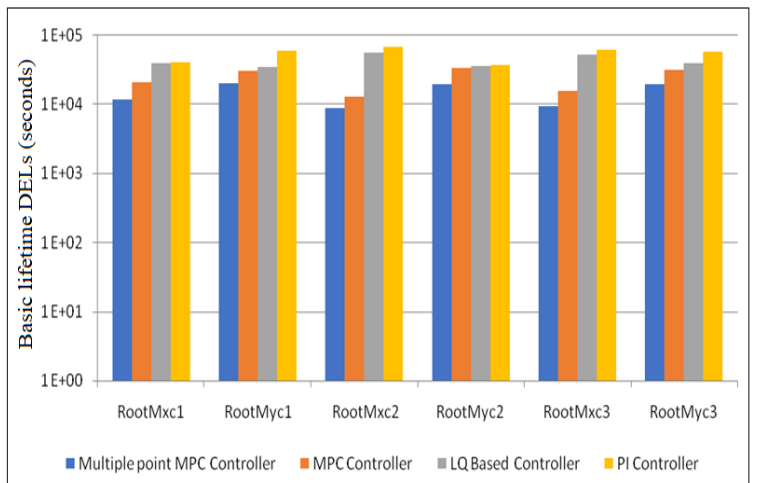

(c)

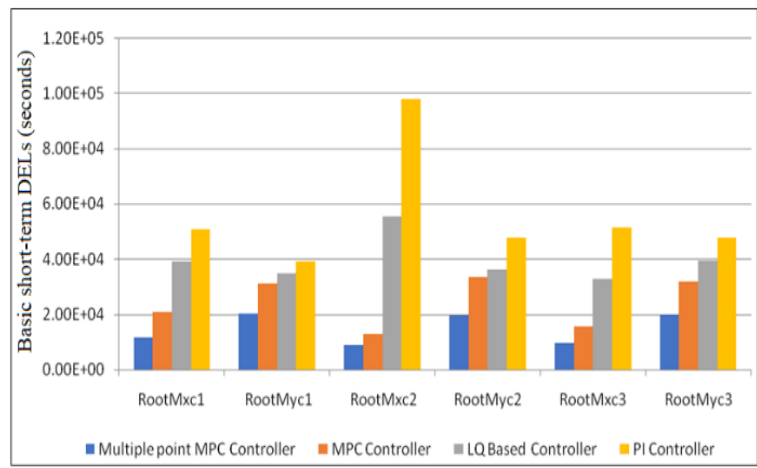

(b)

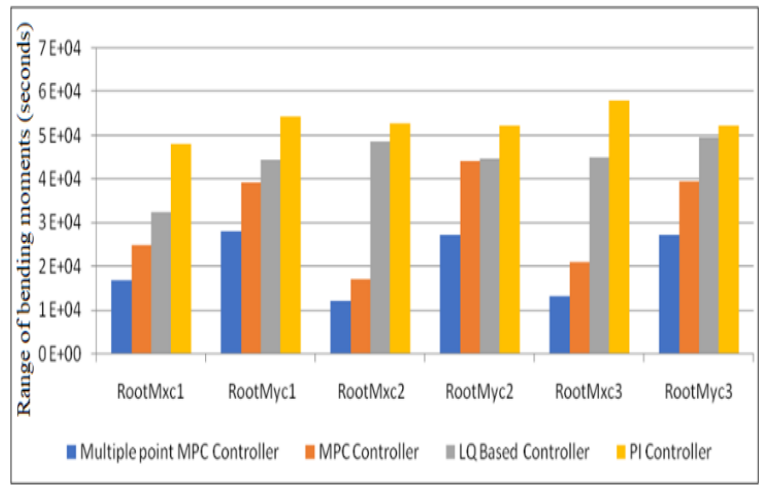

(d)

Figure 9. There figures are, (a) basic lifetime until failure, (b) basic short term DELs, (c) basic Lifetime DELs, (d) blade root bending moment for the individual using different controllers

A comparative analysis is carried out between different controllers from the histograms shown above and illustrated in Table 2 and Table 3. The efficiency of the proposed system is assessed and compared with other controllers. It is observed that the efficiency is much improved for a short time and lifetime DELs. Further, the lifetime bending moments are adapted to inspect the lifetime until failure. It is noticed that the proposed controller shows a higher lifetime compared with conventional controllers. The analysis shows that the suggested controller proficiently damps the blade root bending moment of the distinct blades. Notably, both short-term and lifetime DELs are condensed radically, and the component's lifespan is augmented exponentially.

Table 2. Comparison of fatigue load efficiency of the proposed controller

\begin{tabular}{|c|c|c|c|c|}
\hline \multirow[t]{2}{*}{ Fatigue Calculations } & \multirow[t]{2}{*}{ Parameters } & \multicolumn{3}{|c|}{ Efficiency (\%) of the proposed controller over the other controllers } \\
\hline & & PI controller & LQ Based Controller & MPC \\
\hline \multirow[t]{2}{*}{ Lifetime DEL } & $\begin{array}{l}\text { Blade averaged root Flap- wise bending } \\
\text { moment }\end{array}$ & 82.33 & 79.47 & 39.02 \\
\hline & $\begin{array}{l}\text { Blade averaged root edgewise bending } \\
\text { moment }\end{array}$ & 61.55 & 46.32 & 38.20 \\
\hline \multirow[t]{2}{*}{ Short term DEL } & $\begin{array}{l}\text { Blade averaged root Flap- wise bending } \\
\text { moment }\end{array}$ & 84.91 & 72.34 & 39.21 \\
\hline & $\begin{array}{l}\text { Blade averaged root edgewise bending } \\
\text { moment }\end{array}$ & 55.95 & 46.23 & 38.23 \\
\hline
\end{tabular}

Table 3. Comparison of lifetime efficiency of the proposed controller

\begin{tabular}{|c|c|c|c|c|c|}
\hline Lifetime Analysis & Parameters & $\begin{array}{l}\text { PI } \\
\text { controller } \\
(\mathrm{sec})\end{array}$ & $\begin{array}{ll}\text { LQ } & \text { Based } \\
\text { controller } & \\
(\mathrm{sec}) & \end{array}$ & $\begin{array}{l}\text { MPC } \\
\text { Controller } \\
(\mathrm{sec})\end{array}$ & $\begin{array}{l}\text { Multiple Point MPC } \\
(\mathrm{sec})\end{array}$ \\
\hline \multirow{2}{*}{$\begin{array}{l}\text { Lifetime until } \\
\text { failure }\end{array}$} & $\begin{array}{l}\text { Blade averaged root Flap- wise } \\
\text { bending moment }\end{array}$ & $2.37 \mathrm{e}+09$ & $1.27 \mathrm{e}+12$ & $2.02 \mathrm{e}+13$ & $6.549 \mathrm{e}+14$ \\
\hline & $\begin{array}{l}\text { Blade averaged root edge- wise } \\
\text { bending moment }\end{array}$ & $1.837 \mathrm{e}+09$ & $4.765 e+11$ & $1.547 \mathrm{e}+13$ & $8.873 e+13$ \\
\hline
\end{tabular}

Fatigue mitigation of wind turbine system using multiple point model predictive control ... (A. Mutharasan) 


\subsubsection{Tower top bending}

The shear forces affecting the tower top deflection are evaluated from the simulation and used for the lifespan investigation. The statistical illustration of the lifespan examination results is attained and illustrated in Figures 10 (a)-(d). The proposed controller shows better performance for tower top bending parameters such as basic lifetime (until failure), basic short-term DELs, basic lifetime DELs and shear force. Consolidating the outcomes, the proposed MPMPC enhances the WECS with well-controlled fatigue ranges. From the histograms shown in the above figures, the results for tower top deflection due to the tower top shear forces are summarized in Table 4. It associated the efficiency of the proposed controller over the conventional controllers in reducing the fatigue damage that increases the lifetime.

Table 4. Comparison of fatigue load efficiency for tower top deflection

\begin{tabular}{lcccc}
\hline Fatigue Calculations & Parameters & \multicolumn{2}{c}{ Efficiency (\%) of the proposed controller over the other controllers } \\
& & PI controller & LQ Based Controller & MPC Controller \\
\hline Lifetime DEL & Tower top fore-aft shear force & 76.57 & 54.298 & 37.38 \\
& Tower top side-side shear force & 90.11 & 44.89 & 21.74 \\
\hline
\end{tabular}

Consolidating all the inferences, the proposed controller damps the tower top deflection of the wind turbine efficiently due to the shear forces of a nonlinear wind gust. As a result, both short-term and lifetime DELs are condensed significantly, and the component's lifespan is augmented exponentially. The proposed control strategy has more significant advantages from the results, i.e., $70 \%$ effectual than the PI pitch controller, 50\% more effective than the LQ-based controller, and 30\% more effectual than the single-point MPC controller. It can reduce the fatigue load greatly, and the lifetime is amplified significantly.

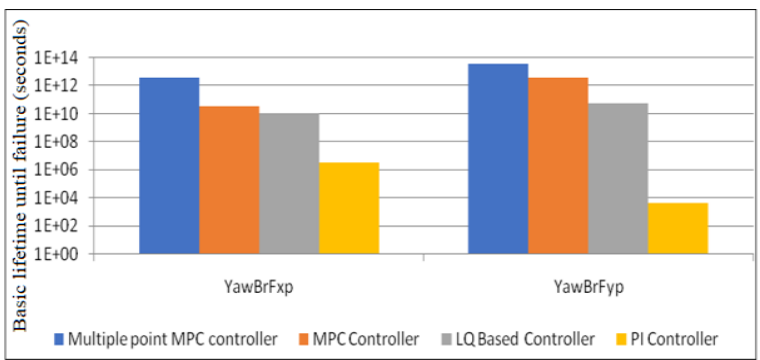

(a)

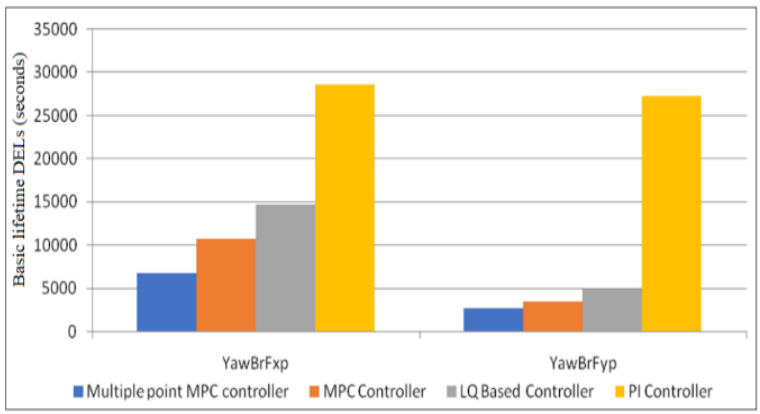

(c)

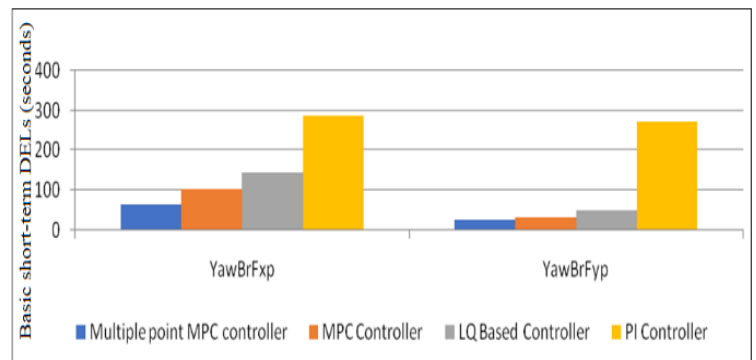

(b)

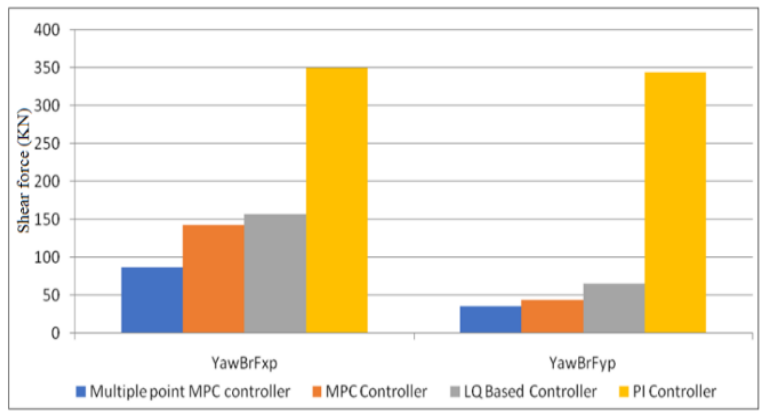

(d)

Figure 10. There figures are, (a) basic lifetime until failure, (b) basic short term DEL, (c) basic Lifetime DEL, (d) shear force at the tower top

\section{CONCLUSION}

This work proposed a new control strategy, namely the MPMPC controller, which effectively mitigates fatigue loads on the WT with an optimum control act compared to other existing controllers. The lifespan evaluation (concerning the individual component) displays a radical enhancement in the lifespan of the WT while using the recommended controller. The equivalent fatigue loads of the features while using the proposed control strategy are less than the other controllers like LQ-based, MPC, and PI controllers, precisely about $37.38 \%$ greater than MPC. The intrinsic constraint handling capability of the recommended controller 
is used to retain the pitching proportion inside the threshold rate to guarantee the constancy of the WT. Since the pitching proportion is optimum, the tradeoff of aerodynamic efficiency is reduced. As a whole, the suggested controller increases the lifespan of the WECS by about $49.50 \%$ greater than MPC and exceedingly more than LQ-based and PI controller that makes the wind power production more economical. It could also pave the way for a lightweight wind turbine with high power handling capacity with reduced cost. This work can be extended by proposing the control strategy for fatigue load mitigation on other components like drive train stress and stress on the yaw mechanism.

\section{REFERENCES}

[1] G. Jackson, and D. Söffker, "State-of-the-art in wind turbine control: trends and challenges," Renewable and Sustainable Energy Reviews, vol. 60, pp. 377-393, 2016, doi: 10.1016/j.rser.2016.01.110.

[2] S. Sbramanian, C. Sankaralingam, R. M. Elavarasan, R. R. Vujayaraghavan, K. Raju, and L. Mihet-popa, "An evaluation on wind energy potential using multi-objective optimization based non-dominated sorting genetic algorithm III," Sustainability, vol. 13, no. 1, p. 410, 2021, doi: 10.3390/su13010410.

[3] B. Aydoğan, "Offshore wind power atlas of the black sea region," Journal of Renewable and Sustainable Energy, vol. 9, no. 1, p. 013305, 2017, doi: 10.1063/1.4976968.

[4] V. S. S. Balaguru, N. M. J. Swaroopan, K. Raju, M. H. Alsharif, and M.-K. Kim, "Techno-economic investigation of wind energy potential in selected sites with uncertainty factors," Sustainability, vol. 13, no. 4, p. 2182, 2021, doi: $10.3390 / \mathrm{su} 13042182$

[5] M. Rajalakshmi, S. Chandramohan, K. Raju, M. H. Alsharif, M.-K. Kim, and N. Jamel, "Design and validation of BAT algorithm-based photovoltaic system using simplified high gain quasi boost inverter," Energies, vol. 14, no. 4, p. 1086, 2021, doi: 10.3390/en14041086.

[6] R. Krishnamoorthy, U. Kaithamalai, K. Raju, R. M. Elavarasan, and L. Mihet-popa, "An assessment of onshore and offshore wind energy potential in India using moth flame optimization," Energies, vol. 13, no. 12, p. 3063, 2020, doi: 10.3390/en13123063.

[7] R. M. Elavarasan et al., "A holistic review of the present and future drivers of the renewable energy mix in Maharashtra, State of India," Sustainability, vol. 12, no. 16, p. 6596, 2020, doi: 10.3390/su12166596.

[8] M. Anthony, V. Prasad, K. Raju, M. H. Alsharif, Z. W. Geem, and J. Hong, "Design of rotor blades for vertical axis wind turbine with wind flow modifier for low wind profile areas," Sustainability, vol. 12, no. 19, p. 8050, 2020, doi: $10.3390 /$ su12198050.

[9] C. Sun, and V. Jahangiri, "Fatigue damage mitigation of offshore wind turbines under real wind and wave conditions," Engineering Structures, vol. 178, pp. 472-483, 2019, doi: 10.1016/j.engstruct.2018.10.053.

[10] E. Mohammadi, R. Fadaeinedjad, and G. Moschopoulus, "Implementation of internal model based control and individual pitch control to reduce fatigue loads and tower vibrations in wind turbines," Journal of Sound and Vibration, vol. 421, pp. 132-152, 2018, doi: 10.1016/j.jsv.2018.02.004.

[11] C. Li, T. Zhuang, S. Zhou, Y. Xiao, and G. Hu, "Passive vibration control of a semi-submersible floating offshore wind turbine," Applied Sciences, vol. 7, no. 6, p. 509, 2017, doi: 10.3390/app7060509.

[12] R. Rezaei, P. Fromme, and P. Duffour, "Fatigue life sensitivity of monopile-supported offshore wind turbines to damping," Renewable energy, vol. 123, pp. 450-459, 2018, doi: 10.1016/j.renene.2018.02.086.

[13] P. He, R. Hong, H. Wang, and C. Lu, "Fatigue life analysis of slewing bearings in wind turbines," International Journal of Fatigue, vol. 111, pp. 233-242, 2018, doi: 10.1016/j.ijfatigue.2018.02.024.

[14] T. Buckley, P. Watson, P. Cahill, V. Jaksic, and V. Pakrashi, "Mitigating the structural vibrations of wind turbines using tuned liquid column damper considering soil-structure interaction," Renewable energy, vol. 120, pp. 322 341,2018, doi: 10.1016/j.renene.2017.12.090.

[15] F. Fateh, W. N. White, and D. Gruenbacher, "Torsional vibrations mitigation in the drivetrain of DFIG-based gridconnected wind turbine," in IEEE Transactions on Industry Applications, vol. 53, no. 6, pp. 5760-5767, Nov.-Dec. 2017, doi: 10.1109/TIA.2017.2730159.

[16] J. Yang, E. M. He, and Y. Q. Hu, "Dynamic modeling and vibration suppression for an offshore wind turbine with a tuned mass damper in floating platform," Applied Ocean Research, vol. 83, pp. 21-29, 2019, doi: 10.1016/j.apor.2018.08.021.

[17] D. Giagopoulus et al., "Structural health monitoring and fatigue damage estimation using vibration measurements and finite element model updating," Structural Health Monitoring, vol. 18, no. 4, pp. 1189-1206, 2018, doi: $10.1177 / 1475921718790188$.

[18] B. Fitzgerald, A. Staino, and B. Basu, "Wavelet-based individual blade pitch control for vibration control of wind turbine blades," Structural Control and Health Monitoring, vol. 26, no. 1, p. e2284, 2018, doi: 10.1002/stc.2284.

[19] S. Ebadollahi, and S. Saki, "Wind turbine torque oscillation reduction using soft switching multiple model predictive control based on the Gap Metric and Kalman Filter estimator," in IEEE Transactions on Industrial Electronics, vol. 65, no. 5, pp. 3890-3898, May 2018, doi: 10.1109/TIE.2017.2760841.

[20] X. Huang, T. Pan, Z. Li, S. Ding, and T. Shuai, "Multiple model predictive control with undisturbed switch for wind turbines system," 2017 11th Asian Control Conference (ASCC), 2017, pp. 1080-1085, doi: 10.1109/ASCC.2017.8287321.

[21] M. Rungruanganukul, and T. Siribirvirnratanakul, "Deep learning based gesture classification for hand physical therapy interactive program,"in International Conference on Human-Computer Interaction, Springer, Cham, 2020, pp. 349-358, doi: 10.1007/978-3-030-49904-4_26. 
[22] Y.-C. Du, M. Muslikhim, T.-H. Hsieh, and M.-S. Wang, "S. Stereo vision-based object recognition and manipulation by regions with convolutional neural network. electronics," Electronics, vol. 9, no. 2, p. 210, 2020, doi: 10.3390/electronics9020210.

[23] A. Z. da Costa, H. E. H. Figueroa, and J. A. Fracarolli, "Computer vision based detection of external defects on tomatoes using deep learning. Biosystems Engineering," Biosystems Engineering, vol. 190, pp. 131-144, 2020, doi: 10.1016/j.biosystemseng.2019.12.003.

[24] A. Boloor, K. Garimella, X. He, C. Gill, Y. Vorobeychick, and X. Zhang, "Attacking vision-based perception in end-to-end autonomous driving models," Journal of Systems Architecture, vol. 110, p. 101766, 2020, doi: 10.1016/j.sysarc.2020.101766.

[25] H. Xiaoying, W. Jingcheng, Z. Langwen, and W. Bohui, "Data-driven modelling and fuzzy multiple-model predictive control of oxygen content in coal-fired power plant," Transactions of the Institute of Measurement and Control, vol. 39, no. 11, pp. 1631-1642, 2016, doi: 10.1177/0142331216644498.

[26] Y. Zhang, Y. Bai, and H. Yang, "A universal multiple-vector-based model predictive control of induction motor drives," in IEEE Transactions on Power Electronics, vol. 33, no. 8, pp. 6957-6969, Aug. 2018, doi: 10.1109/TPEL.2017.2754324.

[27] M. Nourbagheri, "Transmission clutch to clutch transient control using multiple model predictive control," Academia Thesis, 2017.

[28] N. M. Neya, S. Saberi, and B. Mozafari, "Direct predictive speed control of permanent magnet synchronous motor fed by matrix converter," International Journal of Power Electronics and Drive System, vol. 11, no. 4, pp. 21832193, 2020, doi: 10.11591/ijpeds.v11.i4.pp2183-2193.

[29] M. R. B. Khan, J. Pasupultei, J. Al-Fattah, and M. Tahmasebi, "Energy management system for PV-Battery microgrid based on model predictive control, "Indonesian Journal of Electrical Engineering and Computer Science, vol. 15, no. 1, pp. 20-25, 2018, doi: 10.11591/ijeecs.v15.i1.pp20-26.

\section{BIOGRAPHIES OF AUTHORS}
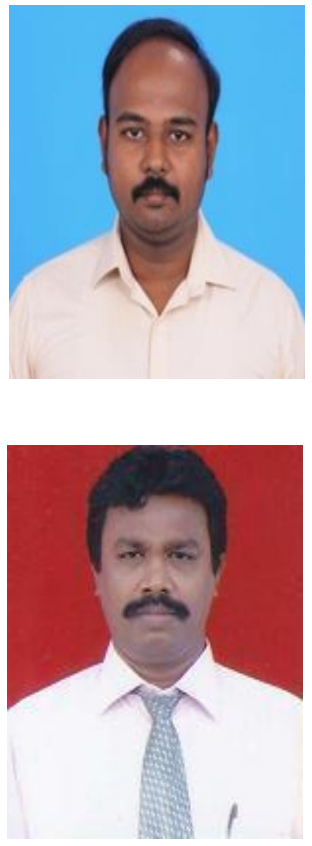

Mutharasan Anburaj, Research Scholar, Department of Electrical and Electronics Engineering, Vel Tech Rangarajan Dr. Sagunthala R\&D Institute of Science and Technology, Chennai. He also works as Assistant Professor in Department of Electronics and Communication Engineering, Vel Tech Rangarajan Dr. Sagunthala R\&D Institute of Science and Technology, Chennai. He obtained his Masters in M.Tech Power Electronics from Vel Tech Rangarajan Dr.Sagunthala R\&D Institute of Science and Technology, Chennai in 2012. His areas of Interest are Wind Turbine System, Wind Energy Conversion System, and Power Electronics. He is Life Member of ISTE and Reviewer in IEEE on Industrial Electronics and Elsevier journal for ECM, Renewable Energy, TELKOMNIKA - IJEE. Scopus ID - 56156861000, ORCID- https://orcid.org/00000002-9632-8902

Chandrasekar Perumal, Professor, Department of Electrical and Electronics Engineering, Vel Tech Rangarajan Dr. Sagunthala R\&D Institute of Science and Technology, Chennai. He finished his $\mathrm{PhD}$ in Power Quality monitoring and analysis, Anna University, Chennai. His research interests include signal processing applications of power quality and reliability analysis, Wavelet analysis and artificial intelligence to power system, Image Processing, Smart grid and Renewable Energy. Teaching experience about 21 years and associated with professional societies namely ISTE and IEEE, USA. Published 35 research papers in National and International conferences. Scopus ID - 37055539700, ORCID - https://orcid.org/0000-0002-9513-4401 